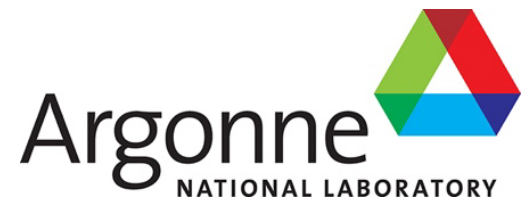

ANL-VTR-87 Rev. 1

\title{
Status of EM Pump Modeling Capability for VTR
}

Nuclear Science and Engineering Division 


\title{
About Argonne National Laboratory \\ Argonne is a U.S. Department of Energy laboratory managed by UChicago Argonne, LLC under contract DE-AC02-06CH11357. The Laboratory's main facility is outside Chicago, at 9700 South Cass Avenue, Argonne, Illinois 60439. For information about Argonne and its pioneering science and technology programs, see www.anl.gov.
}

\section{DOCUMENT AVAILABILITY}

Online Access: U.S. Department of Energy (DOE) reports produced after 1991 and a growing number of pre-1991 documents are available free at OSTI.GOV (http://www.osti.gov/), a service of the US Dept. of Energy's Office of Scientific and

Technical Information.

\author{
Reports not in digital format may be purchased by the public from the \\ National Technical Information Service (NTIS): \\ U.S. Department of Commerce \\ National Technical Information Service \\ 5301 Shawnee Rd \\ Alexandria, VA 22312 \\ www.ntis.gov \\ Phone: (800) 553-NTIS (6847) or (703) 605-6000 \\ Fax: (703) 605-6900 \\ Email: orders@ntis.gov \\ Reports not in digital format are available to DOE and DOE contractors \\ from the Office of Scientific and Technical Information (OSTI): \\ U.S. Department of Energy \\ Office of Scientific and Technical Information \\ P.O. Box 62 \\ Oak Ridge, TN 37831-0062 \\ www.osti.gov \\ Phone: (865) 576-8401 \\ Fax: (865) 576-5728 \\ Email: reports@osti.gov
}

\footnotetext{
Disclaimer

This report was prepared as an account of work sponsored by an agency of the United States Government. Neither the United States Government nor any agency thereof, nor UChicago Argonne, LLC, nor any of their employees or officers, makes any warranty, express or implied, or assumes any legal liability or responsibility for the accuracy, completeness, or usefulness of any information, apparatus, product, or process disclosed, or represents that its use would not infringe privately owned rights. Reference herein to any specific commercial product, process, or service by trade name, trademark, manufacturer, or otherwise, does not necessarily constitute or imply its endorsement, recommendation, or favoring by the United States Government or any agency thereof. The views and opinions of document authors expressed herein do not necessarily state or reflect those of the United States Government or any agency thereof, Argonne National Laboratory, or UChicago Argonne, LLC.
} 
ANL-VTR-87 Rev. 1

\section{Status of EM Pump Modeling Capability for VTR}

prepared by

Daniel J. O'Grady, Chris Keckler, and Thomas H. Fanning

Nuclear Science and Engineering Division, Argonne National Laboratory

December 2021 


\begin{abstract}
SAS4A/SASSYS-1 is a simulation tool used to perform deterministic analyses of anticipated events as well as design basis and beyond design basis accidents for advanced liquid-metalcooled nuclear reactors. Most recently, SAS4A/SASSYS-1 has been selected as the safety analysis software for the Versatile Test Reactor (VTR), a new materials testing Sodium Fast Reactor (SFR) to be built by the Department of Energy. In order to support analysis of the VTR, which will utilize ElectroMagnetic (EM) pumps as the primary coolant pumps, the development of new EM pump modeling capabilities has been initiated for SAS4/SASSYS-1. The new physics-based EM pump model captures systems-level transient performance based on equivalent circuit theory and is highly flexible to model a wide range of electromagnetic pumps of the three-phase linear induction type subject to changes in power supply and plant conditions. Within the equivalent circuit framework, two sub-models are developed to provide options for analysts both with and without a detailed geometric characterization of their pump such that minimal information is required to achieve a realistic working model, but specific details of a particular pump design may be captured if sufficient information is provided. In addition, heat generated from pump operation and its transport through the plant system can be modeled to better capture the behavior of certain transients. This paper will outline the model and derive the governing equations of the new EM pump model. An initial comparison between the simple EM pump model and experimental data is made. This comparison shows that the equivalent circuit model can capture pump performance, with greater accuracy near the rated conditions. In order to demonstrate the transient behavior of the new model, a simple transient with an EM pump replacing the centrifugal pumps in the Advanced Burner Test Reactor is included.
\end{abstract}





\section{Table of Contents}

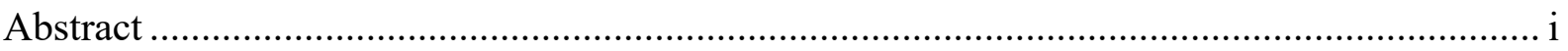

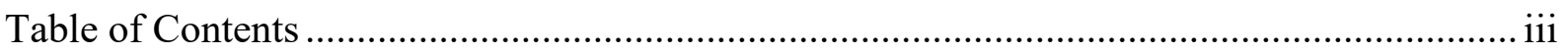

List of Figures ........................................................................................................... iv

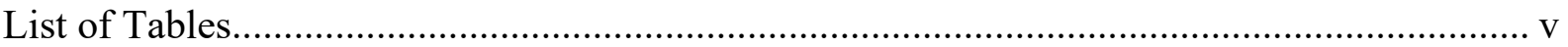

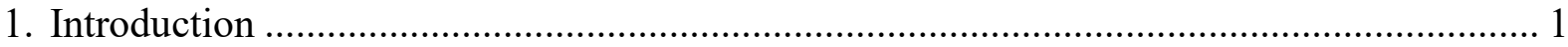

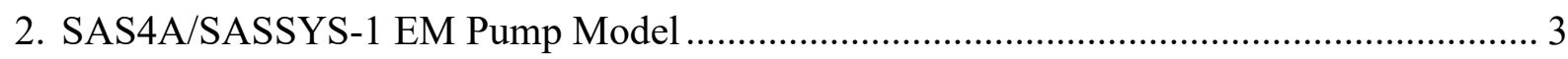

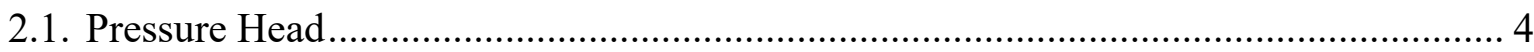

2.1.1. Detailed EM Pump Model …………………............................................. 4

2.1.2. Simple EM Pump Model........................................................................... 4

2.2. Temperature Dependent Circuit Parameters ……………………………………..... 5

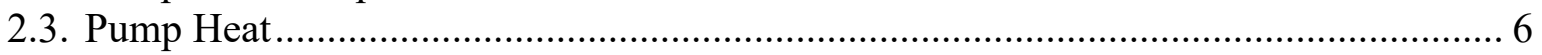

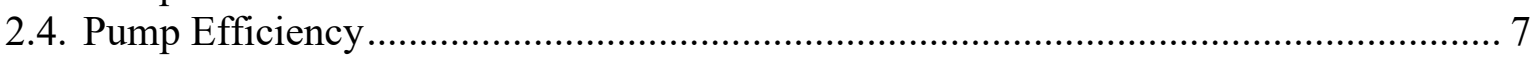

2.5. Equivalent Circuit Limitations ………………………………………………….... 7

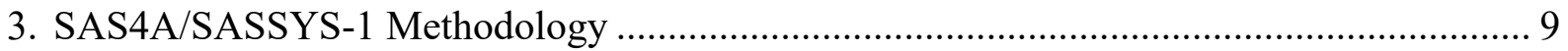

3.1. SAS4A/SASSYS-1 EM Pump Modeling Methodology ……………………………... 12

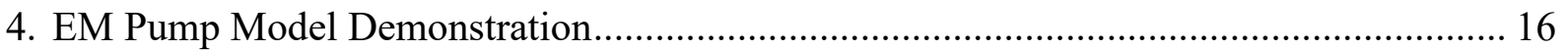

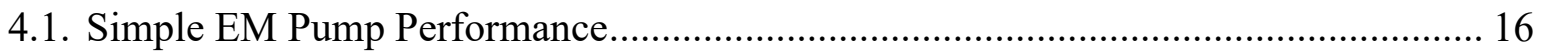

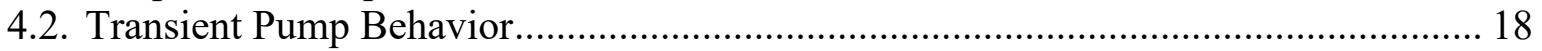

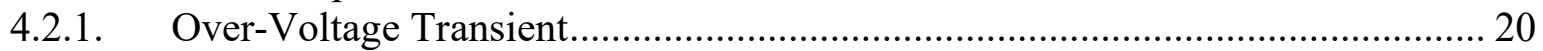

4.2.2. Over-Frequency Transient ......................................................................... 22

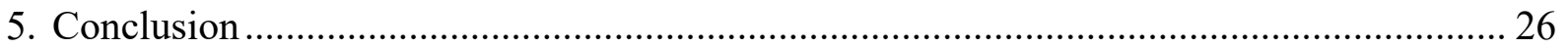

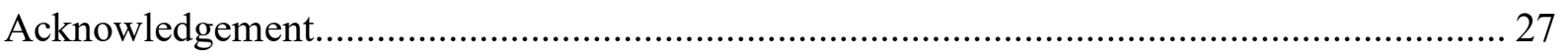

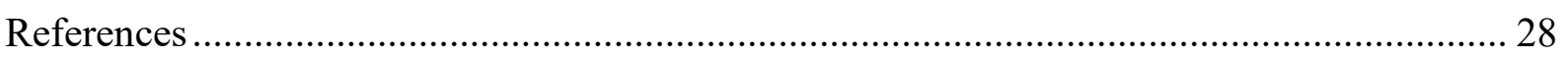




\section{List of Figures}

Figure 1 Detailed equivalent circuit of one phase of an ALIP......................................... 4

Figure 2 Simple equivalent circuit of one phase of an ALIP......................................... 5

Figure 3 Example EMPUMP block input format specification....................................... 12

Figure 4 Steady State Initialization Workflow for EM Pump Models............................... 13

Figure 5 Program flow during a transient calculation for the new EM pump models...... 15

Figure 6 Comparisons of experimental data and curves predicted using the simple circuit model: developed pressure (left) and efficiency (right). Experimental data is the dots, predictions using Case (A) data are solid lines, and predictions using Case

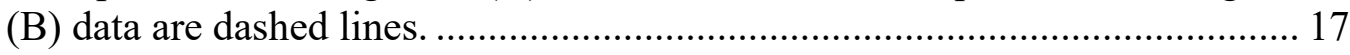

Figure 7 Modified ABTR Geometry including experimental EM pump.......................... 18

Figure 8 Simple EM pump input for over-voltage transient accounting for pump heating.

Figure 9 Relative pump head following a pump over-voltage......................................... 20

Figure 10 Relative flow rate following a pump over-voltage.......................................... 21

Figure 11 Relative core power following a pump over-voltage. ....................................... 21

Figure 12 Inlet plenum temperature following a pump over-voltage............................... 21

Figure 13 Outlet plenum temperature following a pump over-voltage............................ 22

Figure 14 Upper cold pool temperature following a pump over-voltage.......................... 22

Figure 15 Relative pump head following a pump over-frequency. …………………...... 23

Figure 16 Relative flow rate following a pump over-frequency...................................... 23

Figure 17 Relative core power following a pump over-frequency................................. 24

Figure 18 Inlet plenum temperature following pump over-frequency............................ 24

Figure 19 Outlet plenum temperature following pump over-frequency.......................... 24

Figure 20 Upper cold pool temperature following pump over-frequency....................... 25 


\section{List of Tables}

Table 1 Detailed EM Pump model input description.................................................... 10

Table 2 Simple EM pump model input description. ..................................................... 11

Table 3 Rated conditions used for two cases of the simple circuit model........................ 16 


\section{Introduction}

SAS4A/SASSYS-1 (SAS) [1] is a simulation tool used to perform deterministic analysis of anticipated events as well as design basis and beyond design basis accidents for advanced liquid-metal-cooled nuclear reactors. With its origin as SAS1A in the late 1960s, the SAS series of codes has been under continuous use and development for over fifty years and represents a critical investment in safety analysis capabilities for the U.S. Department of Energy. Most recently, SAS4A/SASSYS-1 has been selected as the safety analysis software for the Versatile Test Reactor (VTR), a new materials testing Sodium Fast Reactor (SFR) to be built by the Department of Energy. The VTR, in addition to offering high levels of fast flux, will incorporate a number of novel cartridge loops for testing materials in conditions prototypic of other reactor environments. While highly innovative, the inclusion of cartridge loops imposes constraints on the above-core space in addition to those constraints already present in typical SFR designs. In order to make efficient use of the limited above-core space, ElectroMagnetic (EM) pumps have been selected as the VTR's primary pumps.

EM pumps use fluctuating electromagnetic fields to induce a driving Lorentz force on an electrically conductive fluid without the need for any moving parts or mechanical seals. The design paradigms used for inducing the Lorentz force span a range of options including conduction vs. induction, single- vs. poly-phase, direct vs. alternating current, and straight vs. twisted channels. A broad overview of different EM pump types can be found in [2]. Since EM pumps are not as common as centrifugal pumps, the associated modeling tools are generally less developed and/or not compatible with modern EM pump designs, as is the case for the modeling capabilities of SAS. Existing pump models in SAS include a generic head vs. time option, a variety of centrifugal pump options, and two legacy EM pump options. The first EM option is essentially a curve fit with little physics built in and limited ability for generic pump control, and for these reasons is not satisfactory for the analyses required to authorize the VTR. The second EM option, developed during the Advanced Liquid Metal Reactor (ALMR) program, is an improvement over the first option in that it incorporates constitutive models to a greater extent and offers more flexibility in terms of pump control. Regardless, the ALMR pump option suffers from a few drawbacks because it has embedded within it assumptions specific to the pumps designed under that program, including the assumption that the pump is coupled to a motor-generator set and the inclusion of a number of pump-specific correlations of limited applicability.

Therefore, a program was initiated to develop new EM pump modeling capabilities within SAS. The requirements for the new model include the following:

- Ability for integration within the framework of a systems-level code

- Ability to model hydraulic performance as functions of flow rate and temperature

- Ability for generic pump control through the power supply voltage and frequency (independently)

- Integration of pump control mechanisms with the SAS control system

- Flexibility to model a range of relevant pump designs over conditions in all four flowpressure quadrants 
- Incorporation of pump heating models

- Model option that allows for representation of realistic pump behavior given limited user input

- Possibility for the model to be refined at the expense of additional user input

- Coarse modeling of pump temperatures during operation

To develop a model that meets these requirements, a survey of existing literature was first performed. Recent EM pump modeling efforts have generally focused on using detailed, multiphysics finite element models to better understand unique magnetohydrodynamic flow phenomena, for instance the double-supply-frequency pulsations that occur in finite-length pumps or the suppression of turbulence that results from the induction of EM fields in turbulent eddies [3]. To model EM pumps under this paradigm, it is generally necessary to discretize the coupled set of Navier-Stokes/Maxwell/Lorentz equations over a 3-dimensional, flowing domain and to account for complicated phenomena, such as turbulence and magnetohydrodynamic instabilities. While these types of models are inherently flexible and powerful, the level of detail required to build them along with their computational expense make them not applicable for the intended VTR safety analyses. Just as the complicated fluid phenomena in centrifugal pumps is of little interest in systems-level representations a la homologous pump theory [4], the end application of this work does not call for such refined treatment for EM pumps.

Another form of model in literature is the equivalent circuit [5], used not only for EM pumps but also for other EM devices such as motors and generators [6]. Equivalent circuit models attempt to represent the behavior of EM devices as electrical circuits with design-specific circuit parameters which govern the energy flow through the pump. In analogy to another similar physics problem, equivalent circuit methods are similar to the use of resistance networks in solving for coarse-level fluid flows in piping networks. By assigning different resistances, capacitances, and inductances to different portions of the system, traditional circuit analysis techniques may be used to represent the system dynamics without having to resolve the detailed underlying physics. Examining the model requirements outlined above, it is found that an adaptation of equivalent circuit theory fits all the criteria. Therefore, equivalent circuit theory is the basis for the approach adopted in this work.

Historically, equivalent circuit methods have mostly been used as first-order design tools, however, this work recasts equivalent circuit theory as a modeling tool wherein the pump design is already known, the circuit parameters needed to represent that design are deduced, and the circuit equations are solved subject to power supply and plant state conditions predicted by SAS. This report focuses on describing the equivalent circuit models as implemented in SAS. In Section 2 the features of equivalent circuit theory, including two variants on the same model, are outlined to demonstrate the various features of the model and how they satisfy the requirements of the VTR program. Section 3, outlines how the models, as implemented in SAS, function, including specification of the required user inputs. Section 4 provides a comparison between the SAS EM pump model and experimental data, as well as a demonstration of EM pump model being used within the ABTR primary heat transport system. Finally, a summary of the report, including future work, are presented in Section 5. 


\section{SAS4A/SASSYS-1 EM Pump Model}

The new EM pump models are based on equivalent circuit theory. Equivalent circuit theory is a physics-based model which enables generalized systems-level modeling of EM pumps based on an electric circuit with components that represent the main responses of the pump. Two pump options have been developed: a "detailed" pump option where the characteristics of the electric components are defined by the user, and a "simple" pump option that infers component parameters with limited user input. Though the methodology within SAS for both models is similar, each requires very different levels of effort on the part of the user, with the simple model being nearly "plug-and-play" and the detailed model typically requiring significant offline, up-front modeling efforts before use.

Both models utilize the following underlying assumptions:

1. The pump is induction-type

2. The power source is three-phase alternating current, with each phase equally loaded

3. The three-phase power source is wye-connected

4. Transient performance can be adequately captured using a quasi-static approach.

Assumptions 1-3 serve to limit the scope of which pump types may be modeled, eliminating categories which are not typically relevant to SFR application, such as single-phase or conduction pumps, to enable a unified treatment. While the model was designed with annular linear induction pumps (ALIPs) in mind, the minimal restrictions imposed by the assumptions outlined above enable a large variety of relevant EM pump designs to be included, including both annular and non-annular designs, single- vs. double-stator systems, straight vs. reflux-type flow paths, and those with different working fluids.

Conversely, assumption 4 potentially limits the types of transients which can be modeled. By making a quasi-static assumption, sources of EM inertia are neglected, and the governing circuit equations are solved in steady form at each numerical time step. This assumption is justified on two fronts because (1) EM inertial effects are minimal on the timescales of interest for reactor transients, especially in comparison to centrifugal pumps, and (2) the validity of solving the unsteady circuit equations within the context of EM pump equivalent circuit theory is unknown. Therefore, instead of solving the time-dependent circuit equations in a mode which has unknown validity, it is preferable to clearly state the quasi-static assumption and avoid the computational expense associated with the time-dependent equations.

The new EM pump models are designed to calculate the developed pressure head and total amount of heat being generated within the pump. The design of the pump models is compatible with the existing SAS PRIMAR-4 thermohydraulic methodology. In the following subsections the solution method for both the detailed and the simple EM pump models will be presented, first for determining the developed pressure head, followed by the considerations for pump performance degradation, the calculation of heat being deposited within the pump, and the pump efficiency. In the final subsection the limitations of the EM pump solution are summarized. 


\subsection{Pressure Head}

\subsubsection{Detailed EM Pump Model}

Taking all phases of a three-phase EM pump to be equally loaded, each phase is represented by the diagram in Figure 1, where $R_{1}$ is the primary electrical resistance corresponding to pump windings and other circuitry, $R_{D}$ is the electrical resistance of the duct, $R_{J}$ is the resistance resulting in Joule heating of the fluid, $R_{M}$ is the mechanical work on the fluid, $X_{1}$ is the coil leakage reactance, $X_{2}$ is the magnetizing reactance, $V_{s}$ is the phase voltage of the pump power source, $I$ is the total current, $s$ is slip, and $f$ is the source frequency.

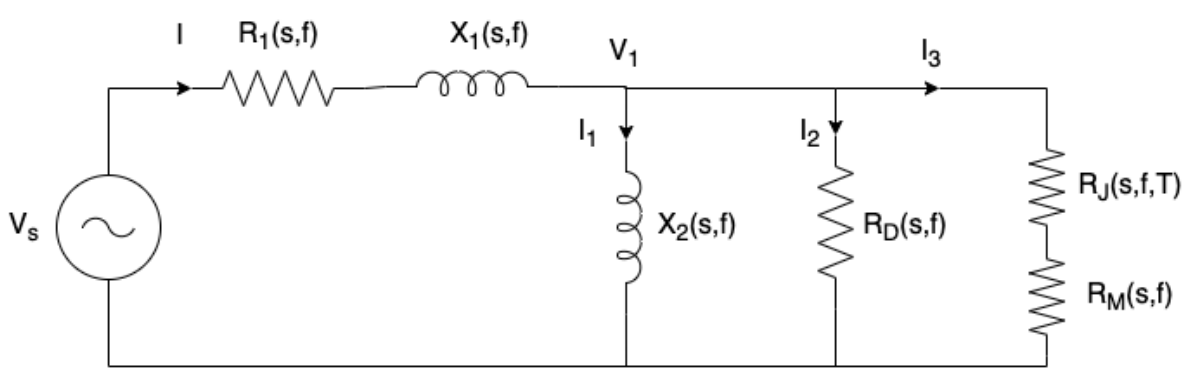

Figure 1 Detailed equivalent circuit of one phase of an ALIP.

By equating the circuit prediction for electrical power dissipated by the fluid with the hydraulic power imparted to the fluid and taking the complex magnitude, the pressure developed by the pump can be predicted as in Equation (1), where $Q$ is the volumetric flow rate.

$$
\Delta P_{P}=\frac{3 I^{2} R_{M}}{Q} \psi
$$

where

$$
\psi=\frac{R_{D}^{2} X_{2}^{2}}{\left(R_{j}+R_{m}\right)^{2} R_{D}^{2}+\left(R_{J}+R_{m}+R_{D}\right)^{2} X_{2}^{2}}
$$

To utilize this model in SAS, the user provides values for all circuit resistances and inductances. In general, each of the circuit parameters in Figure 1 may be functions of operating slip and frequency, and thus the model implementation allows the user to specify slip and frequency functionalities of each parameter using function blocks. Actual determination of pump parameters and their functional dependencies is outside the scope of this work.

\subsubsection{Simple EM Pump Model}

In addition to the above circuit model, a second simplified circuit model, shown in Figure 2, is available to allow users with limited pump information to utilize the EM pump physics. In the simple circuit, the following assumptions are made in comparison to the detailed circuit model: $R_{D}=\infty, R_{J}=0$, and $R_{M}=\frac{R_{2}}{s}$, where $R_{2}$ is a new constant resistance. In addition, the remaining circuit parameters are assumed to be constants. To account for the fact that $R_{2}$ would 
still have a notable dependence on slip due to its inclusion of $R_{M}$, its assumed dependency on slip is explicitly written out so that $R_{2}$ itself is a constant.

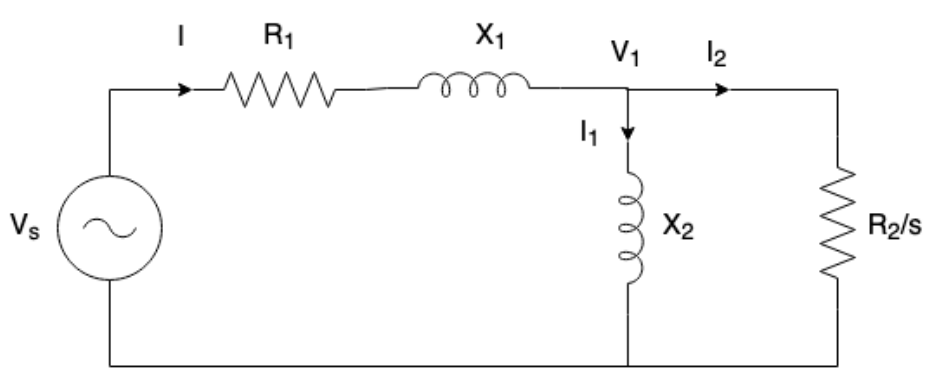

Figure 2 Simple equivalent circuit of one phase of an ALIP.

In this case, the developed pump pressure is calculated according to Equation (3), where $A$ is the pump flow area and $v_{S}$ is the pump synchronous speed.

$$
\Delta P_{P}=\frac{3 I^{2} R_{2}(1-s)}{Q s\left(\frac{R_{2}^{2}}{X_{2}^{2} s^{2}}+1\right)}=\frac{3 I^{2} R_{2}}{A v_{s}\left(\frac{R_{2}^{2}}{X_{2}^{2} s}+s\right)}
$$

For the simplified circuit model, the user provides pump performance data at a single set of "rated" conditions, from which the code uses circuit analysis and the above equations to back out the circuit parameters for the pump. In this way, the user can use the equivalent circuit model to predict pump performance without having detailed knowledge of the pump geometric design.

\subsection{Temperature Dependent Circuit Parameters}

Because EM pumps rely upon electrical current passing through its components, increases in the electrical resistivity of components at elevated temperatures degrade performance by leading to increased Joule heating. This is especially pronounced with relation to the coolant electrical resistivity. Whereas some engineering flexibility exists to optimize duct materials and geometries with respect to electrical resistivity, the coolant material and volumetric flow are mostly determined by considerations of core performance, meaning that the coolant's suitability for use as working fluid in an EM pump may not be ideal. In the case of sodium, as will be used for VTR, the electrical resistivity may be somewhat lower than that of the duct material, but its dependence on temperature is much stronger. In addition, there is generally a larger crosssectional area of sodium in large capacity pumps than there is of duct. These two facts combine to mean that the degradation of coolant electrical resistivity at elevated coolant temperatures is dominant.

To account for this effect, the developed circuit models allow for the resistances capturing Joule heating to scale with the coolant's electrical resistivity evaluated at the current coolant temperature. This is done by assuming a direct proportionality between the associated circuit resistance, $R_{i}$, and the coolant electrical resistivity, $\rho_{r}(T)$, as in Equation (4) and (5), where $R_{J}(s, f, T)$ and $R_{2}(T)$ are the temperature-modified version of $R_{J}$ for the detailed model and $R_{2}$ 
for the simple model, and $T_{R}$ is the rated pump temperature. The user has the ability to neglect this temperature dependence, in which case $R_{J}(s, f, T)=R_{J}(s, f)$ or $R_{2}(T)=R_{2}$.

$$
\begin{gathered}
R_{J}(s, f, T)=\frac{\rho_{r}(T)}{\rho_{r}\left(T_{R}\right)} R_{J}(s, f) \\
R_{2}(T)=\frac{\rho_{r}(T)}{\rho_{r}\left(T_{R}\right)} R_{2}
\end{gathered}
$$

Currently, SAS includes an electrical resistivity correlation for sodium as in Equation (6) [7], with the option for the user to specify alternative correlation coefficients for use with alternative coolants or in place of the built-in sodium correlation. Further, if the user wishes to ignore the impact of temperature on coolant resistivity, it may be disabled entirely.

$$
\rho_{r}(T)=7.756 * 10^{-8}+2.054 * 10^{-10} T+3.481 * 10^{-13} T^{2}
$$

\subsection{Pump Heat}

When solving for the temperature of an EM pump, the governing equations of the pump temperature are the same as a standard pipe or an annular pipe, in the case of an ALIP. In order to allow for inherent modeling of EM Pump heat, the SAS temperature calculations within the heat transport system were updated to account for uniform volumetric heat sources, $q^{\prime \prime \prime}=q / V$, where $q$ is the total heat generation rate and $V$ is the volume of the component. Equations (7) and (8) describe the conservation of energy within the coolant and wall, respectively, of a pipelike component in the heat transport system.

$$
\begin{gathered}
\rho_{\mathrm{c}} C p_{c} A_{c} \frac{\partial T_{c}}{\partial t}=\operatorname{Ph}\left(T_{w}-T_{c}\right)+q_{c}^{\prime} \\
\mathrm{M}_{\mathrm{w}} C p_{w} \frac{\partial T_{w}}{\partial t}=P h\left(T_{c}-T_{w}\right)+(h A)_{s n k}\left(T_{s n k}-T_{w}\right)+q_{w}^{\prime}
\end{gathered}
$$

where $q_{c}^{\prime}=q_{c} / L$ is the linear heat generation rate within the coolant, and $q_{w}^{\prime}=q_{w} / L$ is the linear heat generation rate within the wall. The definition of all other variables can be found in Section 5.4 .1 of [1].

The new EM Pump models calculate $q_{c}$ and $q_{w}$ based on the energy deposited within the circuit resistors. The detailed EM pump circuit contains sufficient information to distinguish between the energy deposited directly in the coolant and the energy deposited within the walls. The energy deposited directly in the coolant, $q_{C}^{D}$, is defined as

$$
q_{c}^{D}=f_{H} 3 I_{3}^{2} R_{J}
$$

where $I_{3}$ is the current that passes through resistor $R_{J}$, and $f_{H}$ is a user-defined sensitivity coefficient. The energy that is deposited in the wall, $q_{w}^{D}$, is defined as 


$$
q_{w}^{D}=f_{H} 3\left(I_{2}^{2} R_{D}+I^{2} R_{1}\right)
$$

where $I_{2}$ is the current that passes through resistor $R_{D}$. The simple EM pump model assumes that $R_{J}=0$ and $R_{D}=\infty$, therefore only heat generated within the pump windings can be quantified. As a result, the energy that is deposited in the wall, $q_{w}^{S}$, is defined as

$$
q_{w}^{S}=f_{H} 3 I^{2} R_{1}
$$

and $q_{c}^{S}=0$.

When annular pipe components are used to represent the geometry of an EM pump, the energy deposited in the wall is distributed between the inner and outer wall of the pipe according to the user input. The temperature calculations for annular pipes within SAS, described in Section 5.4.1.2 in [1], have been updated to account for volumetric heating consistent with the updates described by Equations (7) and (8).

\subsection{Pump Efficiency}

Pump efficiency is a commonly measured parameter and plays an important role in the selection of an EM pump. Because it is commonly measured, the simple EM Pump model uses a rated efficiency to determine some of the circuit parameters. In order to quantify the pump efficiency, the fluid power in the forward direction can be divided by the total electrical power supplied to the pump

$$
\eta=\frac{\Delta P_{p, n e t} \cdot Q}{3 V_{S} I \cos (\phi)}
$$

where $\phi$ is the phase angle between voltage and current and $(\cdot)$ represents the dot product to indicate that positive efficiency results only when flow is in the forward direction. It is noted that such a definition allows for negative efficiencies under reverse flow conditions, when in reality the efficiency under these circumstances would typically be described as "zero". Further, because the orientation of the pump impacts $\Delta P_{p, n e t}$ by potentially changing the sign and magnitude of the gravity term, the efficiency of a given pump may depend on the specifics of its physical implementation. For instance, one could imagine a situation where a pump is oriented vertically with downward flow under the influence of both pump operation and gravity. If the pump were operated at low power, it is possible that gravity pressure could dominate the resulting flow rate such that the definition of efficiency in Equation (12) gives $\eta>1$. Such limitations are inherent in the simplistic definition of efficiency adopted in this work, but under the assumption that $\Delta P_{p} / \Delta P_{p, n e t} \approx 1$, as is the case for the vast majority of real-world reactor pumping systems, these limitations introduce little error. Ultimately, the calculated pump efficiency is not used in any further calculations, with the exception of initializing the simple model, as described in Section 3.2. It is, therefore, reported as an indicator of pump performance that does not directly impact the progression of calculated transients in SAS, meaning any limitations associated with the definition of efficiency are essentially immaterial.

\subsection{Equivalent Circuit Limitations}

Although equivalent circuit theory provides a simple and flexible method of predicting EM pump performance, it is a systems-level model with a few limitations. One of the reasons for equivalent circuit theory straying from experimental results stems from the strong end effects 
displayed by linear EM pumps, resulting from distortion of the magnetic field away from the axial center. These end effects lead to braking forces at the inlet and outlet which can be strongly non-linear and difficult to predict analytically [8], making equivalent circuit theory predictions at operating points sufficiently far from rated conditions subject to uncertainty. A phenomenon intrinsically linked to these end effects is the presence of pulsating pressures at approximately twice the frequency of the power supply. This phenomenon, often termed the Double Source Frequency (DSF) pulsation, leads to pressures which oscillate around the mean value for a given flowrate [3]. Although not having a notable impact on the pump's performance in the system as a whole, these pulsations serve to decrease pump efficiency, and due to the nonlinearity of their magnitude with slip, are difficult to analytically predict [9]. In addition, spatial harmonic interference at design-dependent frequencies can result in developed pressures either higher or lower than would be predicted through the use of equivalent circuit theory [10]. While this may be properly reflected through sufficiently refined use of the detailed circuit model, it may take an extraordinary offline modeling effort to resolve all such effects.

Turbulence effects within EM pumps, especially as related to hydraulic friction losses, are also difficult to accurately capture using the models outlined in this paper. At high flow rates, turbulent eddies lead to perpendicular flow of the highly conductive coolant that interact with the pump's EM field to produce secondary magnetic forces, which in turn act to suppress turbulence. Ultimately this results in less turbulence within the pump than would typically be predicted through traditional Reynold's number-based methods, meaning the friction factor obtained from a Moody diagram will be inaccurate [2]. While this is not a shortcoming of equivalent circuit theory per se, it is a known source of potential inaccuracy that is difficult to resolve without more extensive modeling efforts.

Another effect neglected by equivalent circuit theory is the presence of magnetohydrodynamic instabilities under high-pressure, low-flow conditions which serve to degrade developed pressures [11]. In this regime, strong EM forces drive the fluid in localized regions of the pump faster than the flow rate dictated by the piping system, leading to low pressure in adjacent regions of the flow channel and manifestation of localized, oscillating flow reversals. The presence of this phenomenon can be predicted using the magnetic Reynold's number of the flow, but its impacts on performance are difficult to predict with equivalent circuit theory, especially when rated conditions are specified outside of this unstable region. The issue may be avoided in the detailed circuit model by specifying circuit parameters of sufficient refinement, if the user desires to undertake the required offline modeling.

Finally, equivalent circuit models are not capable of providing insight on a wide variety of performance characteristics of secondary importance, such as the detailed distribution of heat production, the precise temperature of windings or insulation materials, spatial flow distributions within the flow channel, etc. In addition, no literature has been found discussing the application of equivalent circuit models to transient performance. Particularly in the case of very rapid transients when the pump is operating at low frequency, the quasi-static assumption employed in this work may not be valid. For such information, additional modeling and experimentation are necessary. 


\section{SAS4A/SASSYS-1 Methodology}

The required and optional input for the detailed and simple EM Pump models are listed in Table 1 and Table 2, respectively. It is evident from Table 1 and Table 2 that the detailed and simple EM pump models require significantly different input parameters and that the detailed EM Pump model requires the users to define several potentially multi-dimensional functions. In order to allow for the ability to define multiple EM pumps within the primary heat transport system, without utilizing all of the remaining reserved PRIMAR4 input locations, a mixture of existing INPMR4 locations and a new input block are utilized to define simple and detailed EM Pumps.

The new input block, EMPUMP, is stylistically based on the FUNCTION and TABLE block formats (described in section 2.8.1.2 of [1]). EM pump types are specified using a type parameter, DETAILED or SIMPLE. Each EMPUMP block is connected to the associated PRIMAR-4 pump element using the input ILRPMP, for pump type IEMPMP=-3. The new block, shown in Figure 3, allows a user to define pump characteristics using a flexible function or table block, which intrinsically allows the SAS control system to interact with the pump power supply.

In addition to the new pump type, IEMPMP=-3, which tells SAS to use the new EM Pump model, a new element type, ITYPEL=15, was created to allow for pumps to take an annular geometry. The new element type, an annular pump impeller, is analogous to ITYPEL $=13$ for temperature calculations and ITYPEL $=5$ for hydraulic calculations. 
Table 1 Detailed EM Pump model input description.

\begin{tabular}{|c|c|c|c|}
\hline Variable & Input & Range & 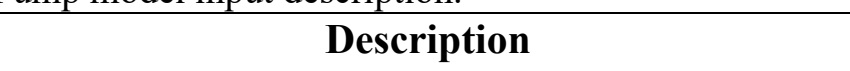 \\
\hline$V(t)$ & VFuncID & - & $\begin{array}{l}\text { Function block number corresponding to the } \\
\text { normalized pump voltage as a function of time. } \\
\text { Optional. If omitted, voltage is held constant at } \\
\text { the steady state voltage. }\end{array}$ \\
\hline$f(t)$ & fFunclD & - & $\begin{array}{l}\text { Function block number corresponding to the } \\
\text { normalized pump frequency as a function of time }\end{array}$ \\
\hline$f_{0}$ & fo & $f_{0}>0$ & Initial frequency of the pump power supply. \\
\hline$T_{R}$ & TR & $T_{R} \geq 0$ & $\begin{array}{l}\text { Temperature of the fluid at rated conditions. } \\
\text { Optional. If } T_{R}=0.0 \text {, or is omitted pump } \\
\text { temperature dependence is disabled. }\end{array}$ \\
\hline$f_{H}$ & $\mathrm{fH}$ & $0 \leq f_{H}$ & $\begin{array}{l}\text { Scaling fraction for pump heating to be included } \\
\text { in thermal calculations. Optional. If } F_{Q}=0.0 \text {, or } \\
\text { is omitted pump heating is disabled. }\end{array}$ \\
\hline$f_{O D}$ & fOD & $0<f_{O D}<1$ & $\begin{array}{l}\text { Fraction of the pump heating to be deposited in } \\
\text { the outer wall of an annular pump element. }\end{array}$ \\
\hline$R_{1}(f, s)$ & R1FunclD & - & $\begin{array}{l}\text { Function block number corresponding to the } \\
\text { primary electrical resistance as a function of } \\
\text { frequency and slip }\end{array}$ \\
\hline$R_{D}(f, s)$ & RDFunclD & - & $\begin{array}{l}\text { Function block number corresponding to the duct } \\
\text { electrical resistance as a function of frequency } \\
\text { and slip }\end{array}$ \\
\hline$R_{J}(f, s)$ & RJFunclD & - & $\begin{array}{l}\text { Function block number corresponding to the fluid } \\
\text { heating resistance as a function of frequency and } \\
\text { slip }\end{array}$ \\
\hline$R_{m}(f, s)$ & RMFuncID & - & $\begin{array}{l}\text { Function block number corresponding to the fluid } \\
\text { mechanical resistance as a function of frequency } \\
\text { and slip }\end{array}$ \\
\hline$L_{1}(f, s)$ & L1FuncID & - & $\begin{array}{l}\text { Function block number corresponding to the coil } \\
\text { leakage inductance as a function of frequency } \\
\text { and slip }\end{array}$ \\
\hline$L_{2}(f, s)$ & L2FuncID & - & $\begin{array}{l}\text { Function block number corresponding to the } \\
\text { magnetizing inductance as a function of } \\
\text { frequency and slip }\end{array}$ \\
\hline$v_{s}$ & vs & $v_{s}>0$ & $\begin{array}{l}\text { Synchronous pump speed corresponding to initial } \\
\text { power supply frequency. }\end{array}$ \\
\hline
\end{tabular}


Table 2 Simple EM pump model input description.

\begin{tabular}{|c|c|c|c|}
\hline Variable & Input & Range & Description \\
\hline$V(t)$ & VFuncID & - & $\begin{array}{l}\text { Function block number corresponding to the } \\
\text { normalized pump voltage as a function of time. } \\
\text { Optional. If omitted, voltage is held constant at the } \\
\text { steady state voltage. }\end{array}$ \\
\hline$f(t)$ & fFunclD & - & $\begin{array}{l}\text { Function block number corresponding to the } \\
\text { normalized pump frequency as a function of time }\end{array}$ \\
\hline$f_{0}$ & fo & $f_{0}>0$ & Initial frequency of the pump power supply. \\
\hline$\Delta P_{R}$ & $\mathrm{dPR}$ & $\Delta P_{R}>0$ & $\begin{array}{l}\text { Developed pressure over the pump at rated } \\
\text { conditions }\end{array}$ \\
\hline$W_{R}$ & WR & $W_{R}>0$ & $\begin{array}{l}\text { Mass flow rate through the pump at rated } \\
\text { conditions }\end{array}$ \\
\hline$\Delta P_{S}$ & dPS & $\Delta P_{s}>0$ & $\begin{array}{l}\text { Developed pressure over the pump at stall } \\
\text { conditions at rated voltage and frequency }\end{array}$ \\
\hline$\eta_{r}$ & etaR & $0<\eta_{r} \leq 1$ & Fractional pump efficiency at rated conditions \\
\hline$I_{R}$ & IR & $I_{R}>0$ & Phase current at rated conditions \\
\hline$V_{R}$ & VR & $V_{R}>0$ & Phase voltage at rated conditions \\
\hline$f_{R}$ & fR & $f_{R}>0$ & Power supply frequency at rated conditions \\
\hline$s_{R}$ & $\mathrm{sR}$ & $s_{R} \neq 0$ & Slip at rated conditions \\
\hline$\delta_{f p}$ & epsls & $\delta_{f p}>0$ & $\begin{array}{l}\text { Fractional convergence tolerance of the fixed point } \\
\text { iteration to determine stall current. Optional. }\end{array}$ \\
\hline- & iDPOPT & - & $\begin{array}{l}\text { Flag indicating if friction losses are included in } \\
\Delta P_{R} \text {. Optional }\end{array}$ \\
\hline$T_{R}$ & TR & $T_{R} \geq 0$ & $\begin{array}{l}\text { Temperature of the fluid at rated conditions. } \\
\text { Optional. If } T_{R}=0.0 \text {, or is omitted pump } \\
\text { temperature dependence is disabled. }\end{array}$ \\
\hline$f_{H}$ & $\mathrm{fH}$ & $0 \leq f_{H}$ & $\begin{array}{l}\text { Scaling fraction for pump heating to be included in } \\
\text { thermal calculations. Optional. If } f_{H}=0.0 \text {, or is } \\
\text { omitted pump heating is disabled. }\end{array}$ \\
\hline$f_{O D}$ & fOD & $0<f_{O D}<1$ & $\begin{array}{l}\text { Fraction of the pump heating to be deposited in the } \\
\text { outer wall of an annular pump element. }\end{array}$ \\
\hline
\end{tabular}




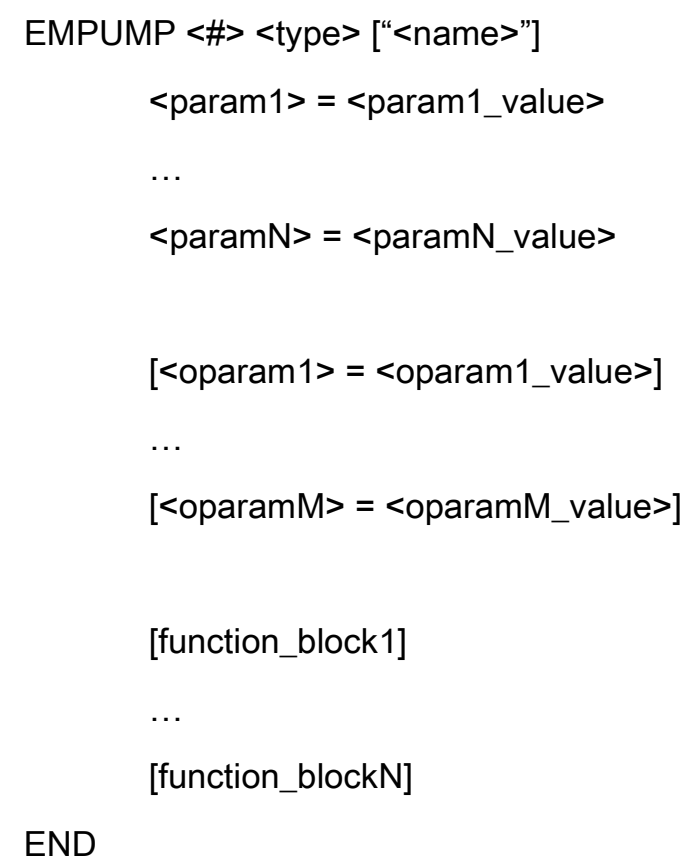

Figure 3 Example EMPUMP block input format specification.

\subsection{SAS4A/SASSYS-1 EM Pump Modeling Methodology}

In order to conform with the existing PRIMAR-4 solution methodology, the new EM pump models were developed to support steady-state initialization, null transient, and transient calculations. During steady state initialization, the EM pump models determine the initial voltage level, as well as other circuit parameters, needed to supply the SAS predicted pump head for the steady-state flow rate. The workflow for both the detailed and the simple EM pump models is shown in Figure 4.

In the detailed circuit model, circuit parameters will be obtained by first evaluating operating frequency at time zero. Using this frequency along with the provided synchronous speed and initial flow rate, the steady state slip is calculated. Then circuit parameters are obtained using the steady state slip and frequency. If the user has selected to account for the temperature dependence of $R_{J}$, the value is scaled using Equation (4). $X_{1}$ and $X_{2}$ are calculated according to the initial frequency, $f=f_{0}$, and the user provided inductance according to Equation (13)

$$
X_{i}=2 \pi f L_{i}(f, s)
$$

In the simple circuit model, the circuit parameters will be obtained from Equations (14) through (17). All values in these equations, except $I_{S}$, are known either from user input $\left(A, \Delta P_{S}, \Delta P_{R}, I_{R}, S_{R}\right)$ or minor manipulations of user input $\left(A_{R} v_{S, R}=\frac{Q_{R}}{\left(1-s_{R}\right)}\right)$. Since $I_{S}$ is not known, a value is assumed, and a fixed-point iteration is used. 


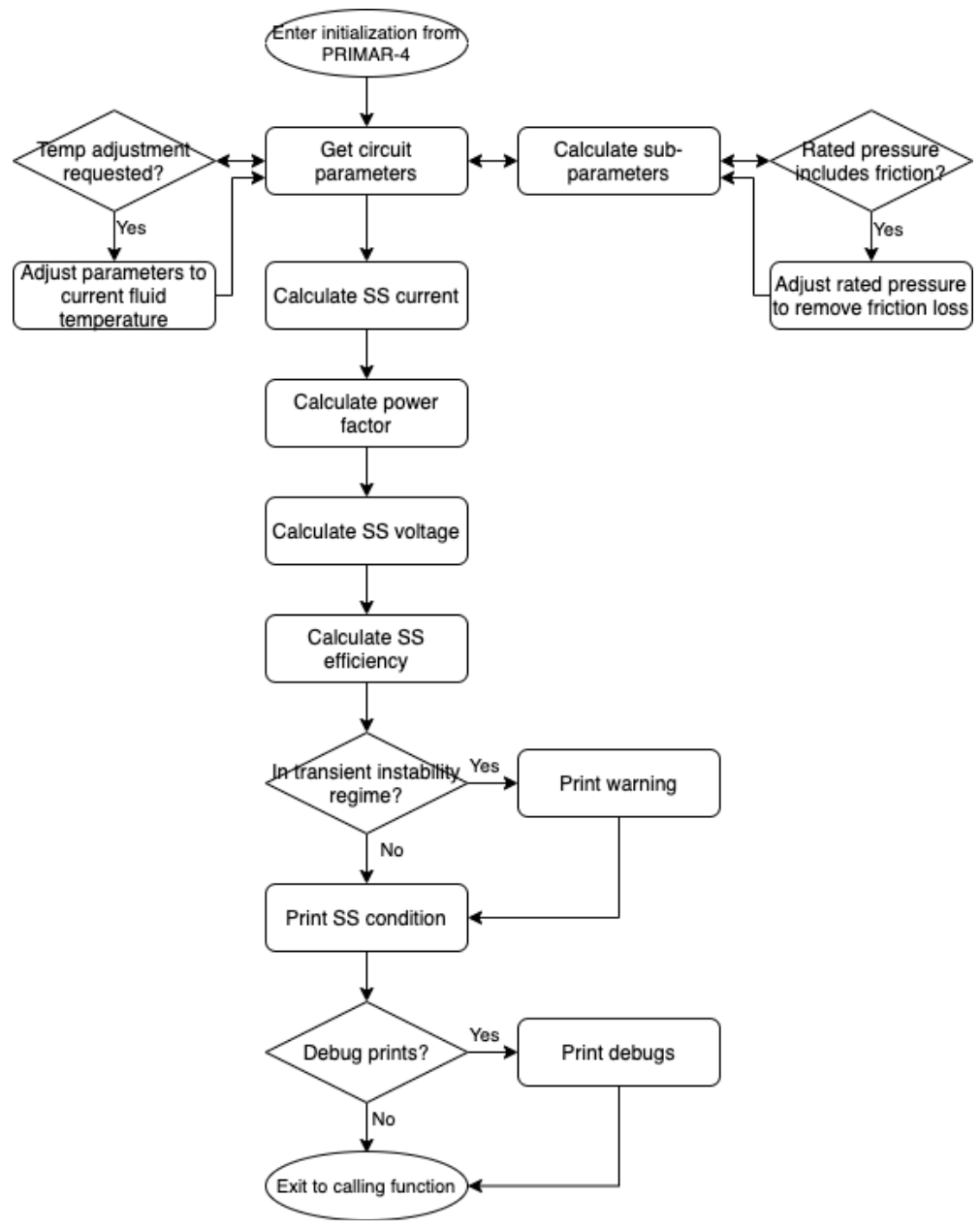

Figure 4 Steady-State Initialization Workflow for EM Pump Models.

Before starting the fixed-point iteration, the simple EM pump model removes frictional pressure losses that may be included in the rated pump head. Using the rated delivered pump head, the simple circuit model solves Equation (3) using the rated and stalled conditions to back out the value of $R_{2}$.

$$
\mathrm{R}_{2}=\frac{\Delta P_{P, R} A v_{S} \frac{\left(s_{R}^{2}-1\right)}{s_{R}}}{3 I_{R}^{2}-\frac{3 I_{S}^{2}}{\Delta P_{P, S} S_{R}} \Delta P_{P, R}}
$$

Using $\mathrm{R}_{2}$ and the rated pump head, $\mathrm{L}_{2}$ can be extracted from Equation (3).

$$
L_{2}=\frac{\mathrm{X}_{2, \mathrm{R}}}{2 \pi f_{R}}=\frac{R_{2} / 2 \pi f_{R}}{\sqrt{\frac{3 I_{S}^{2} R_{2}}{A_{R} v_{s, R} \Delta P_{S}}-1}}
$$


Using the rated efficiency and rated pump head, $R_{1}$ can be backed out of a real power dissipation balance

$$
\mathrm{R}_{1}=\frac{\frac{\Delta P_{R} Q_{R}}{3 I_{R}^{2} \eta_{R}}\left(R_{2}^{2}+X_{2}^{2} s_{R}{ }^{2}\right)-s_{R} R_{2} X_{2}^{2}}{R_{2}^{2}+X_{2}^{2} s_{R}^{2}}
$$

and $L_{1}$ can be backed out of the reactive power dissipation balance

$$
L_{1}=\frac{X_{2, R}}{2 \pi f_{r}}=\frac{\left[\left(\frac{V_{R}}{I_{R}}\right)^{2}-\left(R_{1}+\frac{s_{R} R_{2} X_{2}^{2}}{R_{2}^{2}+s_{R}^{2} X_{2}^{2}}\right)^{2}\right]^{\frac{1}{2}}-\frac{R_{2}^{2} X_{2}}{\left(R_{2}^{2}+X_{2}^{2} s_{R}^{2}\right)}}{2 \pi f_{r}}
$$

Since $I_{S}$ in the above equations is not known a priori, a value will be initially assumed and a fixed-point iteration over this value will be performed using Equations (14) - (17) along with the pressure equation evaluated at $Q=0$ until converged to the tolerance specified by epsls.

Similar to the detailed EM Pump model, if the user has selected to account for the temperature dependence of $R_{2}$, the value is scaled using Equation (5). $X_{1}$ and $X_{2}$ are calculated according to the initial frequency, $f_{0}$, and the calculated inductance using Equation (13).

For either model, the respective pressure equation is then used to determine the steady state pump current at the flow rate and required pump head received from PRIMAR-4 initialization. Using a circuit analysis of the governing circuits in each model, the power factor and voltage are finally determined and pump efficiency at the initial state is calculated. After establishing steady-state pump conditions in either circuit model, the code checks if that pump state is possibly within the "transient instability" regime. By evaluating the pump pressure at a perturbed flow rate, a finite difference approximation to $\left[\frac{\partial \Delta P}{\partial Q}\right]_{Q=Q_{S S}}$ is obtained. In the case that $\left[\frac{\partial \Delta P}{\partial Q}\right]_{Q=Q_{S S}}>0$, the initial pump state may be unstable, and a warning is be printed.

In-between steady-state initialization and the first transient calculation, SAS allows for a null transient, where it begins correcting approximations made during the steady state calculation. For an EM pump element, two approximations are made during the steady state temperature initialization, (1) the pump walls have adiabatic boundary conditions, (2) there is no pump heat. These approximations result in a pump wall temperature that is the same as the coolant temperature. During the null transient calculations, flow rate, pump head and pump heat are held constant while the temperature of the system is allowed to equilibrate under user-provided boundary conditions. Using the component-to-component heat transfer input, the boundary conditions at the surface of an element are updated at the end of each time step to allow for heat transfer between components. Additionally, the pump heat calculated during the steady state initialization is accounted for in the pump coolant and wall temperature calculations. In order to maintain the correct core inlet temperature, the pump heat being produced by each EM pump in the model is added to the total heat that must be removed at the ultimate heat sink of the system. In most cases this is done by increasing the heat rejected at the steam generator. Once 
the temperatures in the system reach a new equilibrium, or a maximum number of null transient time steps has been reached, the null transient ends and the transient calculation begins.

Using the calculated initial voltage and circuit parameters, the new EM Pump models participate in the transient PRIMAR-4 hydraulic calculations. Both the simple and the detailed models use the same algorithm, shown in Figure 5, with different evaluations made at some stages depending on the model. After determining the current power supply voltage and frequency, the EM pump models calculate the slip and update the resistance for the appropriate resistors, if requested. Circuit parameters for the detailed circuit model are evaluated by calls to their respective FUNCTION blocks, whereas they are unchanged from steady state in the simple circuit model. $X_{1}$ and $X_{2}$ are evaluated from $L_{1}$ and $L_{2}$ according to the power supply frequency. The current, pressure, and efficiency equations for the relevant model are then calculated, allowing the EM pump model to update the appropriate terms in the SAS momentum equation (additional details can be found in Section 5.3.4.3 of [1]).

Following the calculation of pump head and current, the EM pump models check if pump heating is enabled, bypassing the remaining routines if not. If pump heating is being accounted for, the models calculate the heat contributions as outlined in Section 2.3. The calculated pump heat is stored for the subsequent temperature calculation of the pump element, where it is assumed to be constant over the time step.

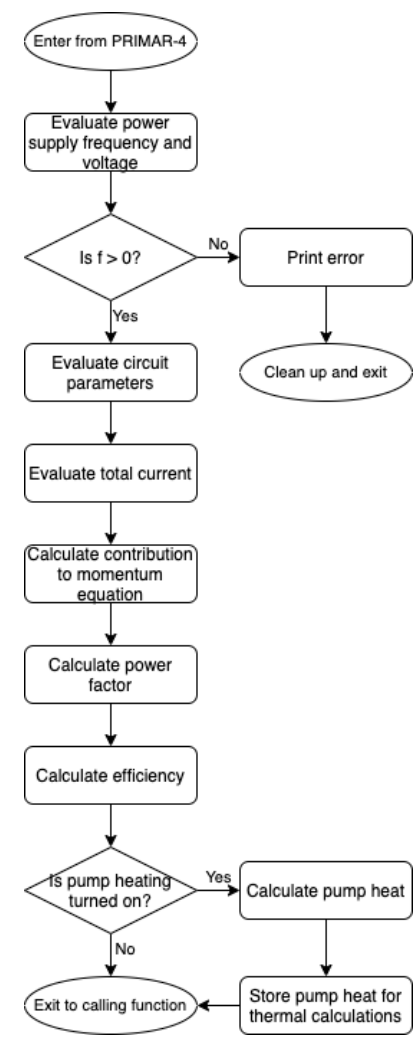

Figure 5 Program flow during a transient calculation for the new EM pump models. 


\section{EM Pump Model Demonstration}

\subsection{Simple EM Pump Performance}

To demonstrate usage of the new models, this section presents an example of the simple circuit model applied to predict the pump curves of a prototypical large capacity sodium EM pump, as outlined by Ota et al. [12]. The referenced pump was designed and built by a team comprised of General Electric, Toshiba, the Japan Atomic Energy Agency, and Kawasaki. Testing reported in the referenced article was performed at the Energy Technology Engineering Center (ETEC) in the early 2000s and consisted of operating the pump at a constant voltage-to-frequency ratio at $355^{\circ} \mathrm{C}$, measuring the pump's developed pressure and calculating efficiency across a range of frequencies and flow rates. This testing sequence resulted in the steady-state pump curves presented in their paper. The purpose of the comparison presented in this section is to demonstrate the accuracy with which the experimental pump curves can be recreated using the simple circuit model, and to understand the impact that selecting different rated conditions can have on the predicted curves. The rated conditions chosen for two different cases, shown in Table 3, are taken directly from [12], where possible, and estimated from related data in circumstances where the data is not directly provided.

Table 3 Rated conditions used for two cases of the simple circuit model.

\begin{tabular}{|l|l|c|c|}
\hline \multicolumn{1}{|c}{ Parameter } & \multicolumn{1}{c}{ Description } & Case A & Case B \\
\hline$\Delta P_{R}(\mathrm{~Pa})$ & $\begin{array}{l}\text { Rated developed } \\
\text { pressure }\end{array}$ & $2.1 \mathrm{E} 5$ & $1.6 \mathrm{E} 5$ \\
\hline$\Delta P_{S}(\mathrm{~Pa})$ & $\begin{array}{l}\text { Rated stall } \\
\text { pressure }\end{array}$ & $2.8 \mathrm{E} 5$ & $2.8 \mathrm{E} 5$ \\
\hline$\eta_{R}(-)$ & Rated efficiency & 0.43 & 0.28 \\
\hline$I_{R}(\mathrm{~A})$ & $\begin{array}{l}\text { Rated phase } \\
\text { current }\end{array}$ & 1684 & 1010 \\
\hline$V_{R}(\mathrm{~V})$ & $\begin{array}{l}\text { Rated phase } \\
\text { voltage }\end{array}$ & 510 & 161 \\
\hline$f_{R}(\mathrm{~Hz})$ & Rated frequency & 12 & 4 \\
\hline$W_{R}(\mathrm{~kg} / \mathrm{s})$ & Rated flow rate & 1333 & 329 \\
\hline$S_{R}(-)$ & Rated slip & 0.21 & 0.42 \\
\hline$T_{R}(\mathrm{C})$ & Rated temperature & 355 & 355 \\
\hline
\end{tabular}

Figure 6 shows the pump curves generated by the simple circuit model with both sets of rated conditions specified in Table 3 superimposed with the experimental data from Ota et al. It is seen that the specific rated conditions utilized to initialize the model have a large impact on the predicted pump curves across different frequencies. While both the pressure and efficiency 
curves generated for frequencies close to the rated frequency are well predicted, those at frequencies higher than the rated frequency are generally overpredicted. This effect is particularly apparent in the efficiency curves, though as noted in Section 2.4, the calculated efficiency is not used in further calculations so the impact of this misprediction is not severe. In light of this trend, it is recommended to specify the rated conditions for a given pump design towards the median of its anticipated operating range to achieve the highest accuracy throughout the transient.

Apart from the mispredictions at frequencies away from the rated frequency, it is seen that the model accuracy is best in the higher-flow region where $\frac{\partial \Delta P}{\partial Q}<0$ and lowest in the low-flow region. This lower accuracy in the low-flow region likely stems from the instabilities and nonlinearities discussed in Section 2.5. Regardless, pump operations in the low-flow regions are typically avoided due to that region often being unstable to changes in flow rate, owing to the fact that $\frac{\partial \Delta P}{\partial Q}>0$, meaning that changes in flow rate are self-reinforcing if other forces do not effectively counteract [12]. Therefore, pump operation is generally kept within the $\frac{\partial \Delta P}{\partial Q}<0$ regime, where the equivalent circuit model is seen to perform best.

Regardless of the inaccuracies observed, it is nevertheless confirmed that the simple circuit model reflects the physical trends in its predictions of pump performance curves, particularly in regions of phase space close to the specified rated conditions. Considering the simplicity of the simple circuit model and the limited effort required on the part of the user, this performance is considered adequate for systems-level modeling of EM pump behavior in SAS. Further, if the user desires higher accuracy, they have the option to utilize the detailed circuit option to effectively achieve arbitrarily accurate predictions.
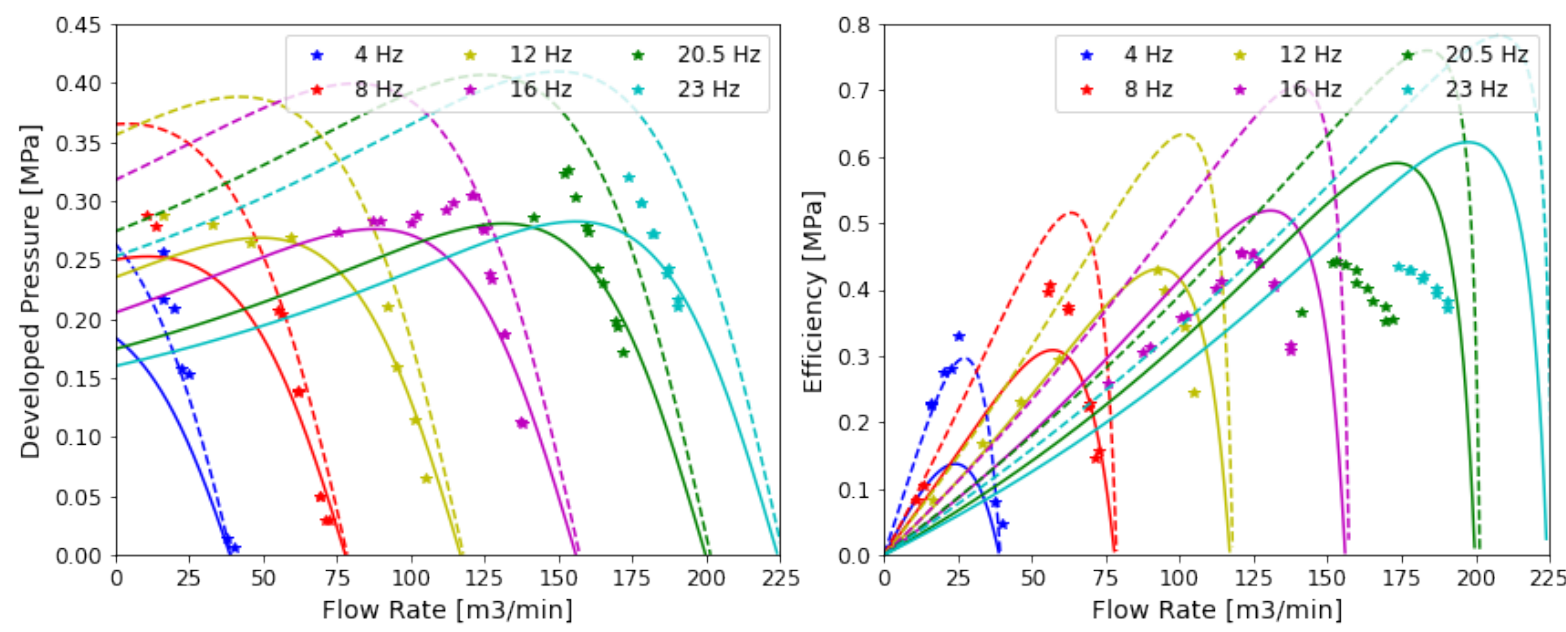

Figure 6 Comparisons of experimental data and curves predicted using the simple circuit model: developed pressure (left) and efficiency (right). Experimental data is the dots, predictions using Case (A) data are solid lines, and predictions using Case (B) data are dashed lines. 


\subsection{Transient Pump Behavior}

In addition to the performance data presented in [12], design parameters are included for the experimental pump. The design parameters include a rated flow rate of $160 \mathrm{~m}^{3} / \mathrm{min}$, or 2300 $\mathrm{kg} / \mathrm{s}$, rated power of $1350 \mathrm{~V}$, rated current of $884 \mathrm{~A}$, a rated frequency of $20 \mathrm{~Hz}$ and a rated slip of 0.16. Using this information, input for a simple EM Pump was created and introduced into an existing Advanced Burner Test Reactor (ABTR) input model [13]. The SAS layout of this modified ABTR model is shown in Figure 7. In order to achieve the rated flow rate of the EM pump, all four of the ABTR's four primary centrifugal pumps are replaced with a single EM pump. Aside from the introduction of the EM pump, the ABTR SAS model is nearly identical to the model described in [13], with the exception of isothermal boundary conditions being applied to the outlet plenum and the upper cold pool.

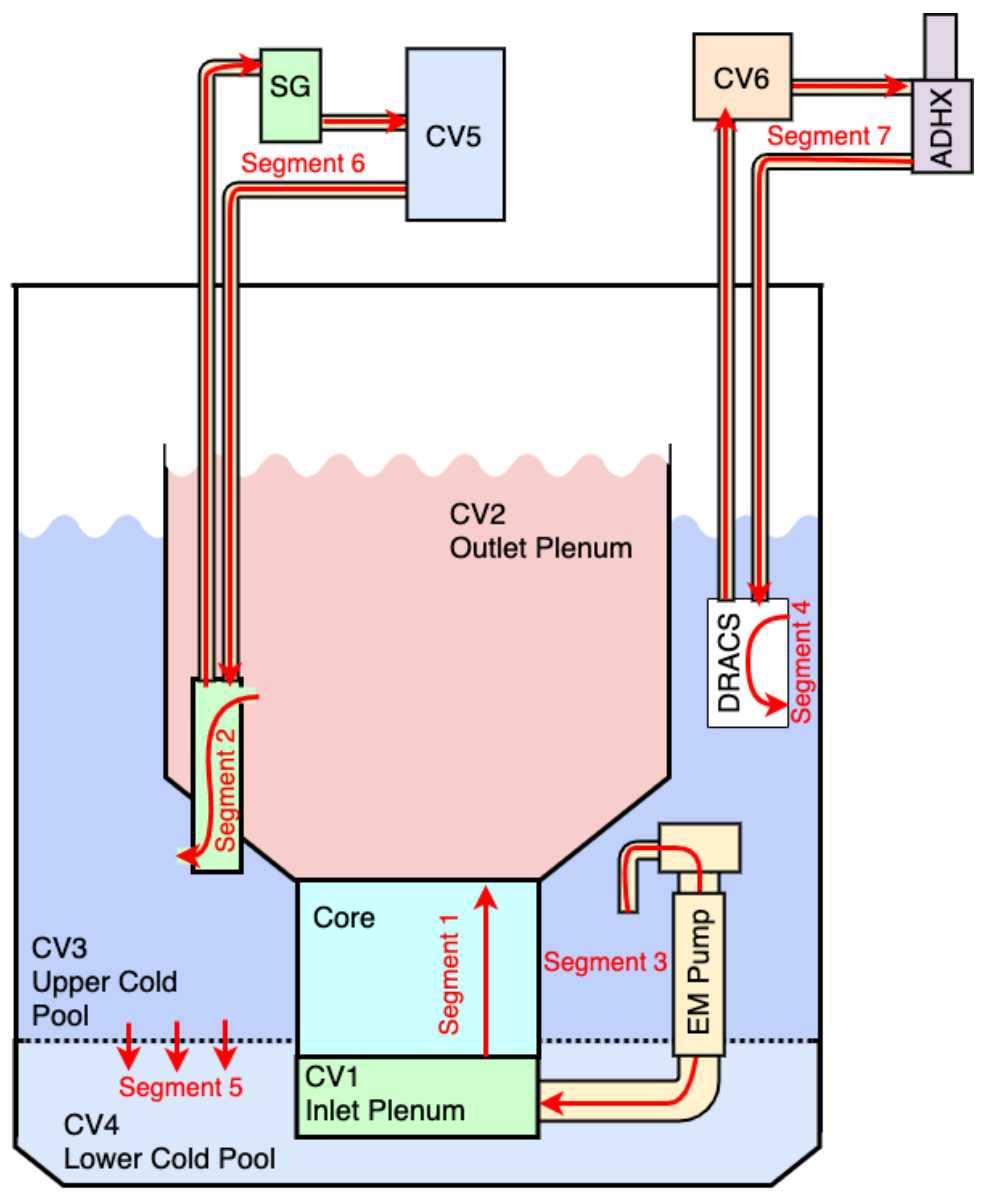

Figure 7 Modified ABTR Geometry including experimental EM pump.

Two transient cases were analyzed using the simple EM pump model. Both transient cases were run twice, once considering pump heat, and once neglecting pump heat. In the first transient, the pump power supply voltage increases by $5 \%$ during a 20 second period, after which the voltage holds constant at $105 \%$. Similarly, in the second transient the pump power supply 
frequency increases by $5 \%$ over a 20 second period, after which it holds constant at $105 \%$. The simple EM pump model input used for the first transient is present in Figure 8.

In order to observe how a pump transient will influence the reactor core, a few approximations were made to the reactor protection system and the primary heat transport system. It is assumed that the reactor protection system does not respond to the pump transient, allowing the reactor to reach a new equilibrium following the transient. Additionally, it is assumed that the temperature of the sodium exiting the steam generator remains at its nominal temperature. All SAS calculations were run for 3400 seconds, with the pump transient initiated at 1000 seconds. Each calculation required 12 seconds on a single computer node.

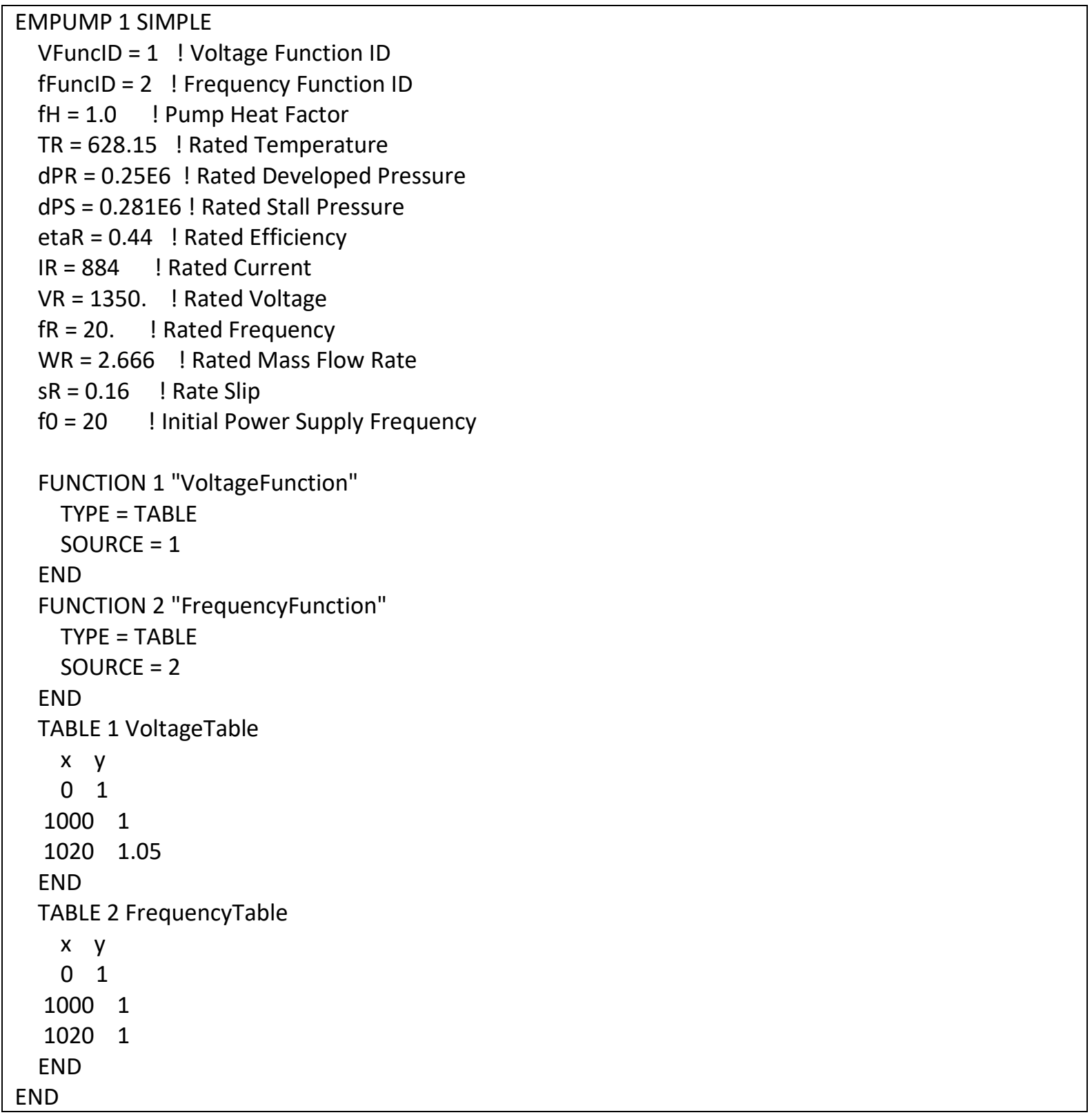

Figure 8 Simple EM pump input for over-voltage transient accounting for pump heating. 


\subsubsection{Over-Voltage Transient}

A five percent increase in pump voltage results in approximately a ten percent increase in pump head, as shown in Figure 9, and a five percent increase in flow rate, as shown in Figure 10. This result is anticipated, as an increase in voltage should be proportional to an increase in current and therefore pressure head. The increase in mass flow rate results in a reduction of core temperature, introducing positive reactivity and an increase in reactor power. The increase in reactor power quickly results in negative reactor feedback, as shown in Figure 11. After approximately 5 minutes the reactor returns to an equilibrium condition at a new power level of $103 \%$.

The impact of the changing power and flow rate can be observed in the temperature of the inlet plenum, outlet plenum and upper cold pool, presented in Figure 12 through Figure 14, respectively. The reduction of the core outlet temperature causes a minor decrease in the outlet plenum temperature. The increasing flow rate causes the temperature of the sodium exiting the intermediate heat exchanger to rise. As a result, the upper cold pool temperature and the inlet plenum temperature rise until they reach a new equilibrium temperature. The impact of the rising core inlet temperature, increased mass flow rate and increase in reactor power cause the outlet plenum to return to its initial temperature.

The impact of pump heating is evident in the upper cold pool. In order to maintain a consistent core inlet temperature between the case considering pump heating and the case neglecting pump heating, the temperature of the sodium exiting the steam generator must be adjusted to account for pump heat. This adjustment results in a larger temperature drop in the steam generator, and therefore a colder upper cold pool, as shown in Figure 14. The over-voltage transient does not appear to have a significant effect on pump heating, although Figure 12 and Figure 13 do show an increase in the temperatures that is consistent with a minor increase in pump heating. It is expected that pump heat would influence pump performance due to the non-linearity of sodium's electrical resistivity and the difference in average temperature within the EM pump. Additional investigation is required to determine why pump performance is not being affected by the changing sodium temperature.

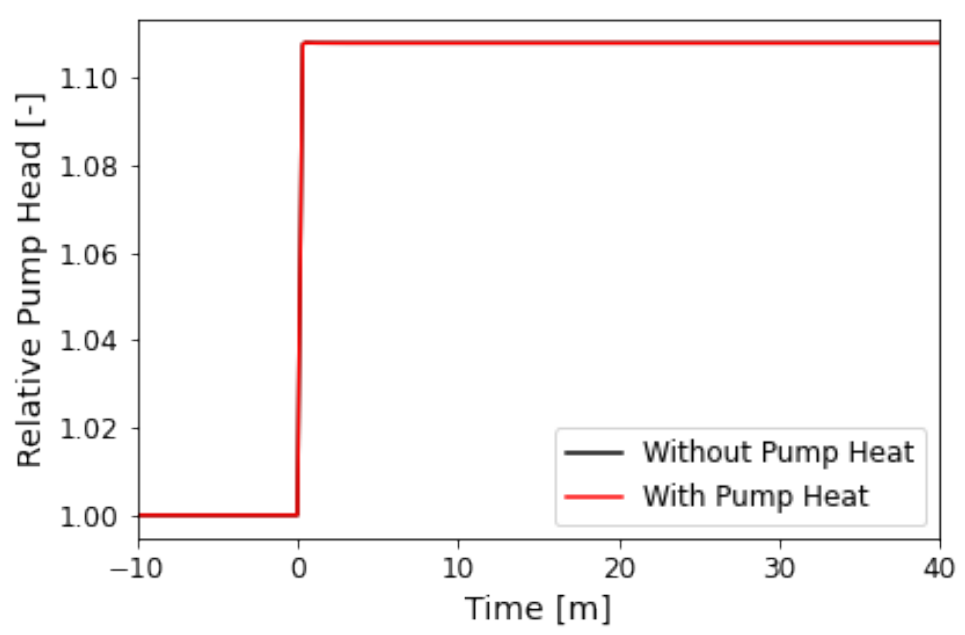

Figure 9 Relative pump head following a pump over-voltage. 


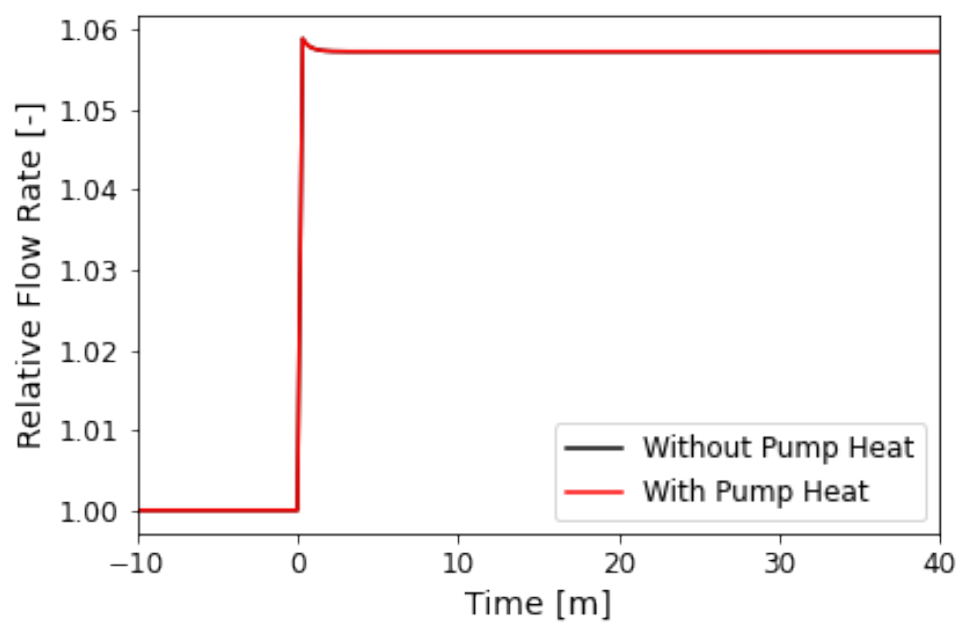

Figure 10 Relative flow rate following a pump over-voltage.

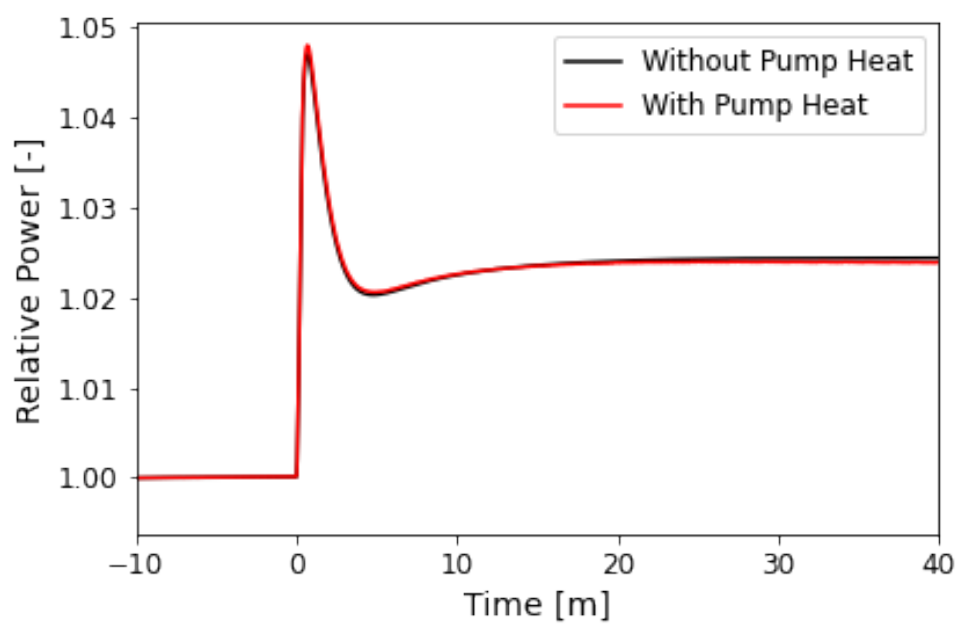

Figure 11 Relative core power following a pump over-voltage.

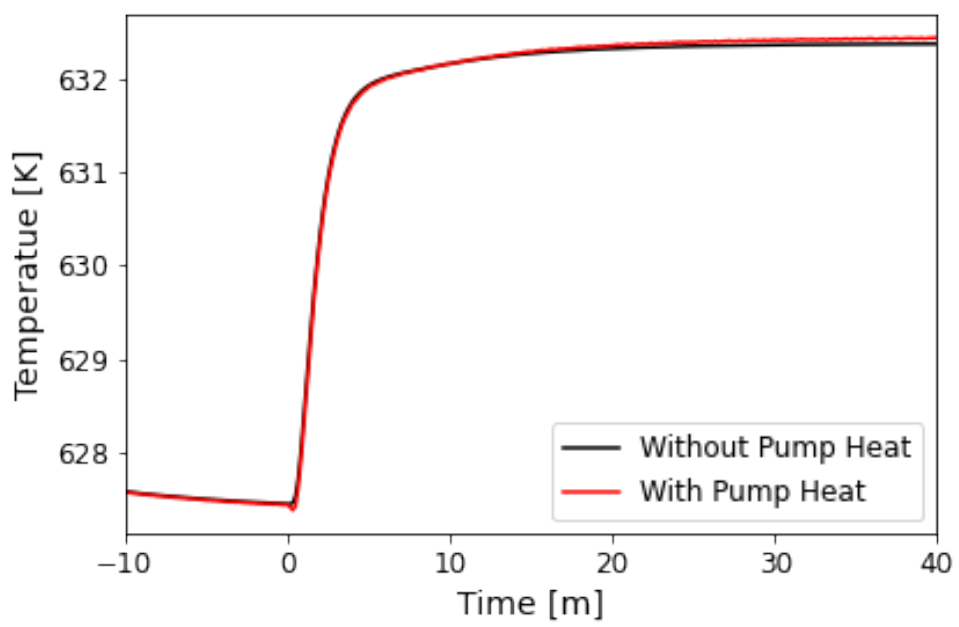

Figure 12 Inlet plenum temperature following a pump over-voltage. 


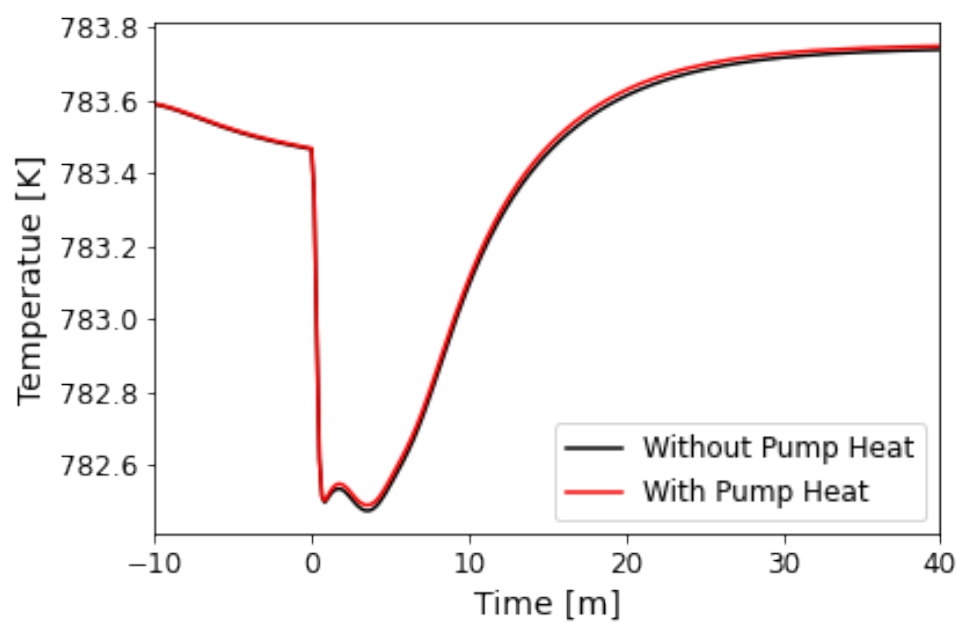

Figure 13 Outlet plenum temperature following a pump over-voltage.

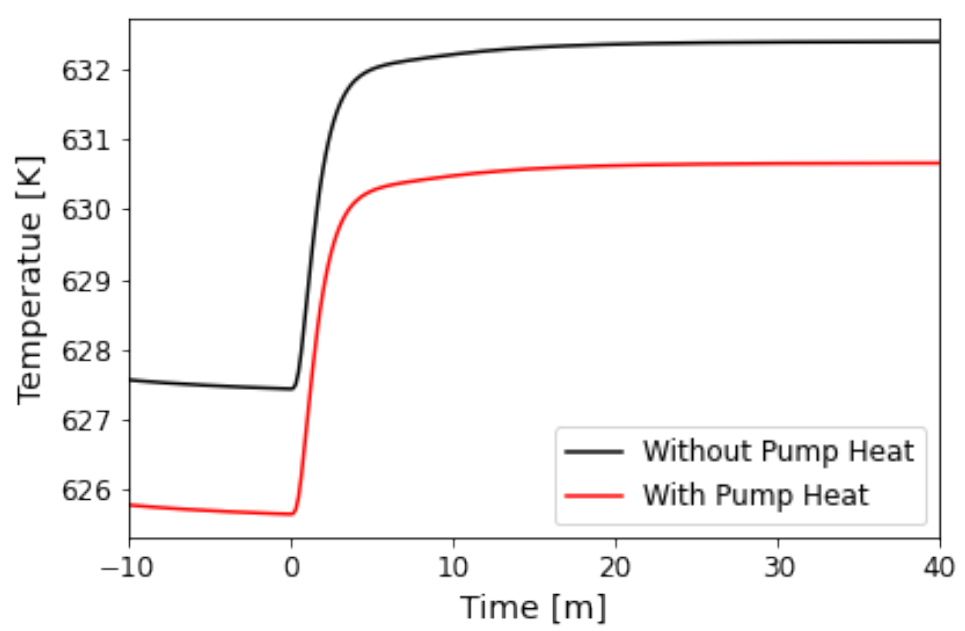

Figure 14 Upper cold pool temperature following a pump over-voltage.

\subsubsection{Over-Frequency Transient}

The five percent increase in pump frequency results in approximately a seven percent decrease in pump head, as shown in Figure 15, and a three percent decrease in flow rate, as shown in Figure 16. This result is expected, as the frequency increases the pump slip increases. An increasing slip results in a decreasing pump head. The decrease in mass flow rate results in an increase of core temperature, introducing negative reactivity and a decrease in reactor power. The decrease in reactor power quickly results in positive reactor feedback, as shown in Figure 17. After approximately 10 minutes the reactor returns to an equilibrium condition at a new power level of $98.5 \%$.

Similar to the over-voltage transient, the impact of the changing power and flow rate can be observed in the temperature of the inlet plenum, outlet plenum and upper cold pool, presented in Figure 18 through Figure 20, respectively. The increase of the core outlet temperature causes a minor increase in the outlet plenum temperature. The decreasing flow rate causes the 
temperature of the sodium exiting the intermediate heat exchanger to decrease. As a result, the upper cold pool temperature and the inlet plenum temperature decrease until they reach a new equilibrium temperature. The impact of the decreasing core inlet temperature, decreasing mass flow rate and decrease in reactor power cause the outlet plenum to return to a slightly lower temperature.

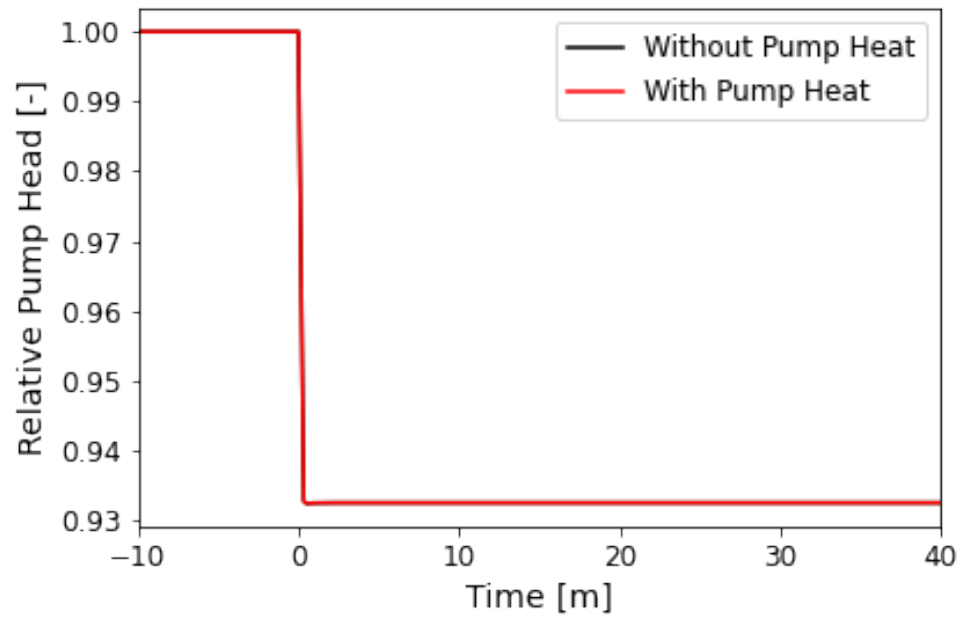

Figure 15 Relative pump head following a pump over-frequency.

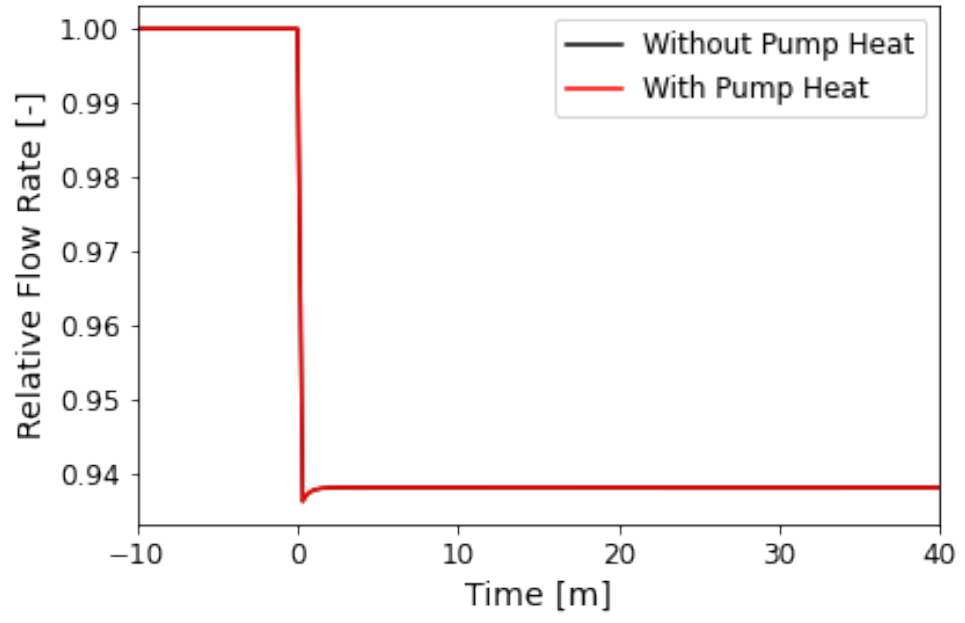

Figure 16 Relative flow rate following a pump over-frequency. 


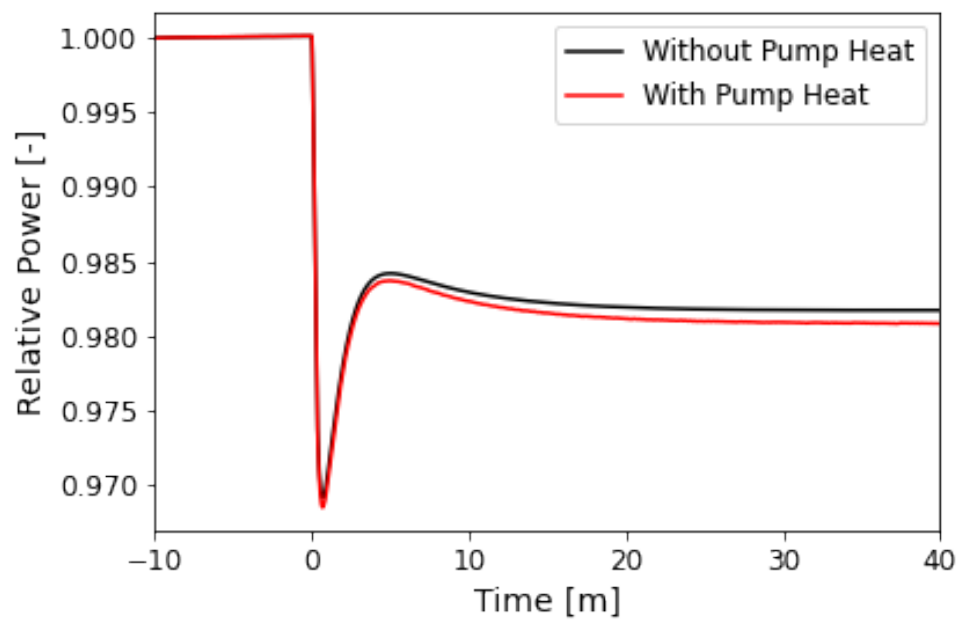

Figure 17 Relative core power following a pump over-frequency.

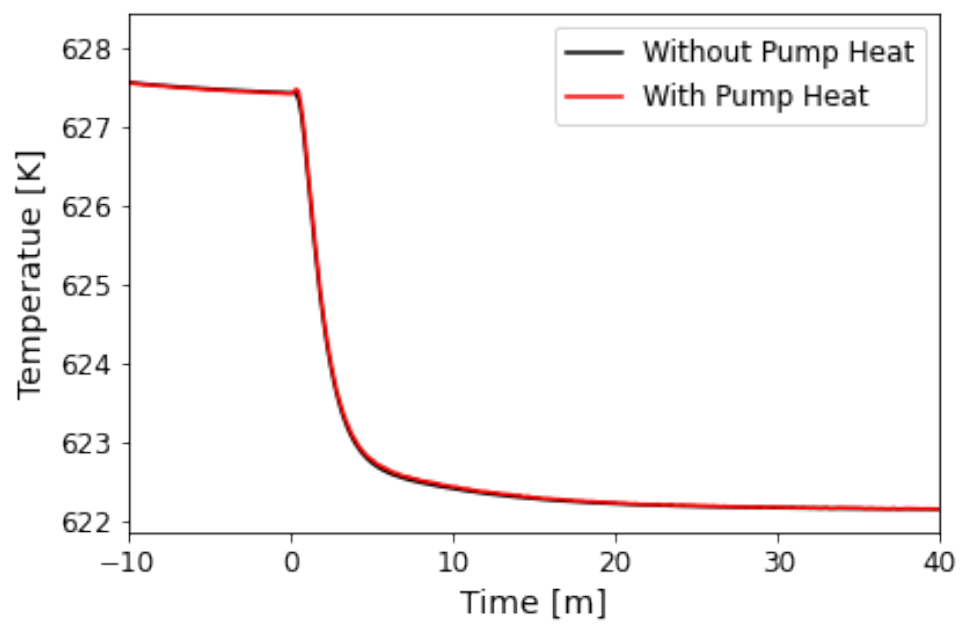

Figure 18 Inlet plenum temperature following pump over-frequency.

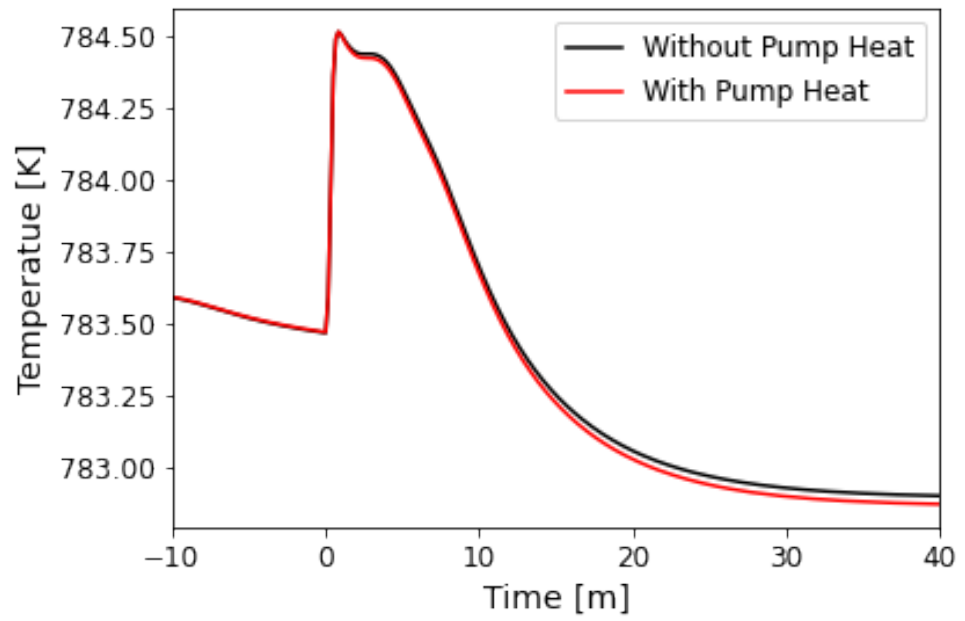

Figure 19 Outlet plenum temperature following pump over-frequency. 


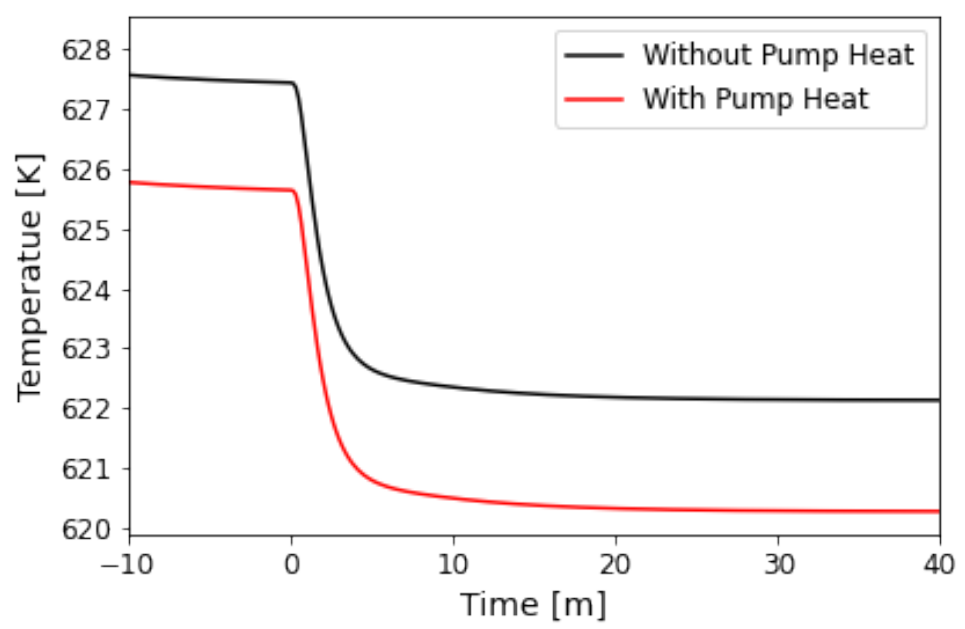

Figure 20 Upper cold pool temperature following pump over-frequency. 


\section{Conclusion}

In order to support the authorization of the VTR, a new EM Pump model was developed for SAS. The new EM pump modeling capability includes the flexibility to model a range of pump designs, generalized pump control, and built-in modeling of pump heating, among other novel features. Built on equivalent circuit theory, the new EM pump model allows users with detailed knowledge of the pump characteristics to predict the system response as a function of frequency and of slip. For cases where pump design is still ongoing, researchers can select a "plug and play" EM pump model based on rated conditions of pump performance. An overview of each modeling options input and underlying theory has been presented.

Although equivalent circuit theory has a few limitations owing to its simplistic representation of a complicated multi-physics system, it has been compared to experimental data and is shown to satisfy the needs of the VTR program. Additionally, the new EM pump model has been demonstrated using a modified ABTR SAS model. The modified ABTR model demonstrated the impact of EM pump heating on the cold pool temperatures and provided confirmation that the SAS EM pump models respond as anticipated to changing voltages and frequencies. Further study is still required to determine why pump performance did not show a dependence on temperature, as anticipated. Additional work is also required to improve the user interface of the new EM pump model, as well as the completion of a SAS Software Quality Assurance procedure for model development. Based on these efforts, the new equivalent circuit pump models will be available to users upon the release of SAS4A/SASSYS-1 v5.5. 


\section{Acknowledgement}

The submitted manuscript has been created by UChicago Argonne, LLC, Operator of Argonne National Laboratory ("Argonne"). Argonne, a U.S. Department of Energy Office of Science laboratory, is operated under Contract No. DE-AC02-06CH11357. 


\section{References}

[1] T. H. Fanning, A. J. Brunett, and T. Sumner, eds., "The SAS4A/SASSYS-1 Safety Analysis Code System: User's Guide," Argonne National Laboratory, Lemont, IL, ANL/NE-16/19, 2017.

[2] L. Blake, "Conduction and induction pumps for liquid metals," Proceedings of the IEE-Part A: Power Engineering, vol. 104, no. 13, pp. 49-67, 1957.

[3] L. Goldsteins, "Experimental and numerical analysis of behavior of electromagnetic annular linear induction pump," Grenoble Alpes; Latvijas universitāte, 2015.

[4] F. Dunn and D. Malloy, "LMR centrifugal pump coastdowns," in Anticipated and abnormal transients in nuclear power plants, 1987.

[5] H. R. Kim and Y. B. Lee, "A design and characteristic experiment of the small annular linear induction electromagnetic pump," Annals of Nuclear Energy, vol. 38, no. 5, pp. 1046-1052, 2011.

[6] E. F. Fuchs and M. A. Masoum, Power conversion of renewable energy systems. Springer Science \& Business Media, 2011.

[7] O. Foust, "SODIUM-NaK ENGINEERING HANDBOOK. VOLUME I. SODIUM CHEMISTRY AND PHYSICAL PROPERTIES," 1972, 1972.

[8] H. R. Kim, "The theoretical approach for viscous and end effects on an MHD pump for sodium circulation," Annals of Nuclear Energy, vol. 62, pp. 103-108, 2013.

[9] M. H. Anderson, J. Rein, M. Hvasta, and W. Nollet, "Enhancement of EM Pump Performance through Modeling and Testing," University of Wisconsin-Madison, 2019.

[10] J. Barnard and G. Collins, Test of 1200-GPM Linear Ac Electromagnetic Pump. US Atomic Energy Commission. Technical Information Service, 1951.

[11] T. Asada, Y. Hirata, R. Aizawa, T. Suzuki, and Y. Fujishima, "Electromagnetic Pump Flow Simulation by 3D MHD Code," in International Conference on Nuclear Engineering, 2014, vol. 45943: American Society of Mechanical Engineers, p. V004T10A031.

[12] H. Ota et al., "Development of $160 \mathrm{~m} 3 / \mathrm{min}$ large capacity sodium-immersed selfcooled electromagnetic pump," Journal of nuclear science and technology, vol. 41, no. 4, pp. 511-523, 2004.

[13] F. Dunn, T. Fanning, and J. Cahalan, "Preliminary safety evaluation of the advanced burner test reactor," ANL-AFCI-172, Argonne National Lab.(ANL), Argonne, IL (United States), 2006. 


\section{Argonne}

Nuclear Science and Engineering Division

Argonne National Laboratory

9700 South Cass Avenue

Argonne, IL 60439

www.anl.gov

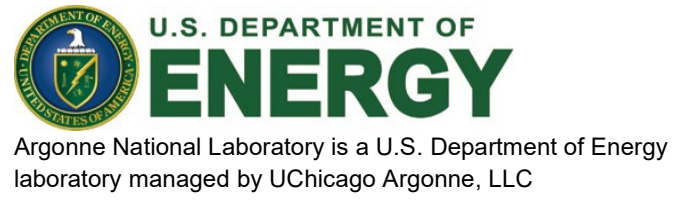

